\title{
8-Propyl-6H-[1,3]dioxolo[4,5-g]chromen-6-one: A new coumarin with monoamine oxidase $B$ inhibitory activity and possible anti-parkinsonian effects
}

\author{
María del Pilar Olaya ${ }^{1 *}$, Nadezdha Esperanza Vergel ${ }^{1}$, Jose Luis López ${ }^{2}$, Dolores Viña ${ }^{\circledR 3}$, \\ Mario Francisco Guerrero ${ }^{1}$
}

\begin{abstract}
${ }^{1}$ Departamento de Farmacia, Facultad de Ciencias, Universidad Nacional de Colombia, Bogotá, Colombia, ${ }^{2}$ Pharmaceutical Chemistry Department, School of Pharmacy, Salamanca University, Salamanca, Spain, ${ }^{3}$ Pharmacology Department, Center for Research in Molecular Medicine and Chronic Diseases, University of Santiago de Compostela, Santiago de Compostela, Spain
\end{abstract}

\begin{abstract}
Parkinson's disease is a common neurodegenerative disorder. In this study, the monoamine oxidase inhibitory activity and potential anti-parkinsonian effects of 8-propyl-6H-[1,3]dioxolo[4,5-g]chromen6-one (FCS303), a new synthetic coumarin, were evaluated. To do this, we used the reserpine model of Parkinson's disease, an assay of levodopa/carbidopa potentiation, the catalepsy model of haloperidol, and an in vitro assay against monoamine oxidase (MAO) activity. Additionally, lipid peroxidation and protein carbonyl group quantification was performed in mice brain homogenates previously treated with haloperidol. FCS303 inhibited monoamine oxidase B (MAO-B) with an $\mathrm{IC}_{50}$ of $5.46 \pm 0.36 \mu \mathrm{M}$; however, there was no effect on monoamine oxidase A (MAO-A). The oral administration of FCS303 led to a significant reversal of hypokinesia in the reserpine model (at $24 \mathrm{~h}$, doses of 100 and $200 \mathrm{mg} / \mathrm{kg}$ ) and in the levodopa/carbidopa potentiation assay (at 2 and $24 \mathrm{~h}$, dose of $200 \mathrm{mg} / \mathrm{kg}$ ). In addition, FCS303 (100 mg/kg) showed anti-cataleptic activity against haloperidol. FCS303 (50 mg/kg) significantly decreased lipid peroxidation and protein carbonyl quantification. These results suggest that FCS303 could present anti-parkinsonian activity related to MAO-B inhibitory activity.
\end{abstract}

Keywords: Parkinson's disease. Monoamine oxidase B. Coumarin. Mice. Reserpine. Levodopa. Carbidopa.

\section{INTRODUCTION}

The World Health Organization (WHO) has estimated that four million people worldwide suffer from Parkinson's disease (PD) (Philippens, 2008). PD is a neurodegenerative disease that is characterized by a loss of dopaminergic neurons of the substantia nigra and basal ganglia. This leads to alteration in the control and coordination of movement. In addition, PD is characterized by muscle rigidity, bradykinesia, resting tremor, and alterations in balance and walking (Alexi et al., 2000; Emborg, 2004).

Levodopa (L-DOPA) is a symptomatic therapy that compensates for the decreased level of dopamine (DA). Monoamine oxidase B (MAO-B) inhibitors have been widely applied in PD (Foley et al., 2000). Interest in

\footnotetext{
*Correspondence: M. Pilar Olaya. Departamento de Farmacia, Universidad Nacional de Colombia. AK 30 \# 45 - 03, 450-215, Bogotá, Colombia. Tel.: +57 13165000 ; ext.: 14622 / Fax:+57 13165060. E-mail: mpolayao@unal.edu.co
}

MAO-B inhibitors was initially stimulated by the desire to elevate the reduced striatal DA concentration, which is characteristic of $\mathrm{PD}$. Selegiline and rasagiline are selective MAO-B inhibitors that continue to be valuable adjunct therapies to L-DOPA for PD (Gershanik, 2015). These agents are very useful in the treatment of disease symptoms in early stage and improve the response to L-dopa in late stage of the disease (Finberg, 2014).

Due to the activity shown in the central nervous system, coumarins have attracted attention in the search for new PD treatments. One study evaluated 1,2-Benzopyrone (obtained from Hygrophila tyttha Leonard species) and found that coumarin was responsible, at least in part, for the anxiolytic, anticonvulsant, and sedative effects described for this species (Ariza et al., 2007). Other coumarins, both natural and modified, have shown antidepressant (Vergel et al., 2010) and neuroprotective effects (Kang et al., 2005; Epifano et al., 2008). Some studies have shown that coumarinic compounds inhibit 
MAO-B (Matos et al., 2004; Matos et al., 2009; Matos et al., 2010; Matos et al. 2013).

In this study, we evaluated the MAO inhibitory activity and potential anti-parkinsonian effects of 8-propyl$6 \mathrm{H}-[1,3]$ dioxolo[4,5-g]chromen-6-one (FCS303), a new coumarin whose spectroscopic data is described below.

\section{MATERIAL AND METHODS}

\section{Drugs and chemicals}

FCS303 was synthesized by the Pechmann reaction (Potdar, Mohile, Salunkhe, 2001), in which coumarin was obtained by condensation of sesamol with ethyl butyryl acetate in the presence of sulphuric acid. The infrared and $1 \mathrm{H} / 13 \mathrm{C}$ magnetic resonance spectra led to the elucidation of the structure of 8-propyl-6H-[1,3]dioxolo[4,5-g] chromen-6-one (Figure 1). FCS303 is an amorphous brown powder, with melting point range of $147-149^{\circ} \mathrm{C}$, and a molecular weight of $232 \mathrm{~g} / \mathrm{mol}$. EI-MS m/z (rel. int.) 232 (96), 217 (5), 204 (12), 189 (20), $176(100), 175$ (90), 159 (15), 145 (3), 131 (7), 115 (5), 103 (6), 89 (10); ${ }^{1} \mathrm{H}$ NMR $\left(200 \mathrm{MHz}, \mathrm{CDCl}_{3}\right): 6.97(1 \mathrm{H}, s, \mathrm{H}-5), 6.81$ $(1 \mathrm{H}, s, \mathrm{H}-8), 6.13(1 \mathrm{H}, s, \mathrm{H}-3), 6.05(1 \mathrm{H}, d, \mathrm{~J}=3.2 \mathrm{~Hz}$, $\left.\mathrm{O}-\mathrm{CH}_{2}-\mathrm{O}\right), 2,64(2 \mathrm{H}, \mathrm{t}, \mathrm{H}=7.9 \mathrm{~Hz}, \mathrm{H}-4 \mathrm{a}), 1.70(2 \mathrm{H}, \mathrm{m}$, $\mathrm{H}-4 \mathrm{~b}), 1.03\left(3 \mathrm{H}, t, \mathrm{~J}=7.5 \mathrm{~Hz}, \mathrm{H}-4 \mathrm{c} ;{ }^{13} \mathrm{C}\right.$ NMR $(75 \mathrm{MHz}$, $\mathrm{CDCl}_{3}$ ) d : 162.1 (s, C-2), 113.2 (d, C-3), 151.8 (s, C-4), 104.9 (d, C-5), 144.5 (s, C-6), 152.6 (s, C-7), 97.8 (d, C-8), 144.8 (s, C-9), 116.0 (s, C-10), 101.9 (t, O- $\left.\mathrm{CH}_{2}-\mathrm{O}\right), 37.1$ (t, C-4a), 21.8 (t, C-4b), 13.5 (q, C-4c).

Others drugs and reagents were used in the experimental procedures, including reserpine, selegiline, L-DOPA, carbidopa, clorgiline and iproniazide which were supplied by Sigma-Aldrich. Haloperidol (Janssen Cilag ${ }^{\circledR}$ ) and a MAO kit (Molecular Probes ${ }^{\circledR}$ ) were also used.

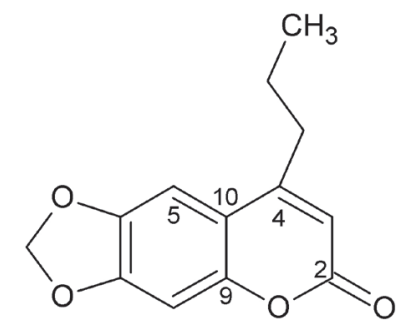

FIGURE 1 - Structure of 8-propyl-6H-[1,3]dioxolo[4,5-g] chromen-6-one (FCS303).

\section{In vitro assay of human monoamine oxidase (hMAO) isoform activity}

The effects of FCS303, clorgiline, selegiline and iproniazide on human monoamine oxidase ( $h \mathrm{MAO}$ ) isoform enzymatic activity were evaluated using a fluorimetric method following the experimental protocol previously described by Yáñez et al. (2006). Briefly, several concentrations of FCS303, and recombinant $h \mathrm{MAO}-\mathrm{A}$ or $h \mathrm{MAO}-\mathrm{B}$ in required amounts adjusted to obtain the same reaction velocity, were incubated with $0.1 \mathrm{~mL}$ of sodium phosphate buffer $(0.05 \mathrm{M}, \mathrm{pH} 7.4)$ at $37^{\circ} \mathrm{C}$ for $15 \mathrm{~min}$ in a flat, black-bottomed 96-well microtest plate in the dark fluorimeter chamber. The experimental conditions were: $h$ MAO-A, $1.1 \mathrm{mg}$ protein; specific activity, $150 \mathrm{nmol}$ $p$-tyramine oxidized to $p$-hydroxyphenylacetaldehyde/min/ mg protein; $h \mathrm{MAO}-\mathrm{B}, 7.5 \mathrm{mg}$ protein; specific activity, $22 \mathrm{nmol} p$-tyramine transformed $/ \mathrm{min} / \mathrm{mg}$ protein.

After the incubation, the reaction was started when $200 \mu \mathrm{M}$ Amplex ${ }^{\circledR}$ Red reagent, $1 \mathrm{U} / \mathrm{mL}$ horseradish peroxidase, and $1 \mathrm{mM} p$-tyramine were added. The production of hydrogen peroxide and, subsequently, of resorufin was quantified in a multi-detection microplate fluorescence reader (FLX800 ${ }^{\mathrm{TM}}$, Bio-Tek ${ }^{\circledR}$ Instruments, Inc., Winooski, VT, USA) at $37{ }^{\circ} \mathrm{C}$, based on the fluorescence generated (excitation: $545 \mathrm{~nm}$, emission: $590 \mathrm{~nm}$ ) over a period of $15 \mathrm{~min}$, in which the fluorescence increased linearly. Simultaneously, control experiments were performed replacing the coumarin analogue or reference inhibitors (clorgiline, selegiline and iproniazide) with suitable dilutions of the vehicles. The capacity of the tested drugs to modify the fluorescence generated in the mixture by directly reacting with Amplex ${ }^{\circledR}$ Red reagent or any non-enzymatic inhibition was determined by adding coumarin analogue and reference solutions containing only the Amplex ${ }^{\circledR}$ Red reagent in a sodium phosphate buffer. The specific fluorescence emission was calculated after subtraction of the background activity, which was determined in vials where all reagents were preserved, except the $h \mathrm{MAO}$ isoforms, which were replaced by a sodium phosphate buffer solution.

\section{In vivo assays}

\section{Animals}

Male ICR mice, weighing between 25 and 30 g, from the Department of Pharmacy, Faculty of Science, Universidad Nacional de Colombia, were used in this study. The animals were housed under standard laboratory conditions, maintained in 12-hour light-dark cycles and at room temperature $\left(22 \pm 1^{\circ} \mathrm{C}\right)$, with food and water available ad libitum.

\section{Non-reserpinized mice}

Mice that did not previously receive reserpine were dosed with compound FCS303 (50, 100, and 
$200 \mathrm{mg} / \mathrm{kg})$, selegiline $(10 \mathrm{mg} / \mathrm{kg})$, or vehicle by oral (p.o.) administration. The pharmacological effect was evaluated at 1.5 and $23.5 \mathrm{~h}$ after administration. This test was performed to observe the results of the administration of selegiline and compound FCS303 in normal mice.

\section{Model of reserpine}

The experimental protocol described by Tadaiesky, Andreatini and Vital (2006) was followed, with some modifications, such as reserpine dose $(3 \mathrm{mg} / \mathrm{kg})$ and evaluation time ( $2 \mathrm{~h}$ and $24 \mathrm{~h})$. The mice were dosed with $3 \mathrm{mg} / \mathrm{kg}$ reserpine by intraperitoneal (i.p.) administration. Selegiline $(10 \mathrm{mg} / \mathrm{kg}), \mathrm{FCS} 303$ (50, 100 , and $200 \mathrm{mg} / \mathrm{kg}$ ), or vehicle were administered orally $30 \mathrm{~min}$ later. Locomotor activity was evaluated using the openfield test, at 2 and $24 \mathrm{~h}$ after reserpine administration. Each animal was placed in the center of the open-field test, and the number of squares crossed was counted for a duration of $5 \mathrm{~min}$. The vehicle used comprised 15\% glycerol, $15 \%$ propylene glycol, and distilled water in sufficient quantity to make up $100 \%$.

\section{Potentiation of the effect of L-DOPA/carbidopa in} mice pre-treated with reserpine

Reserpine ( $3 \mathrm{mg} / \mathrm{kg}$ ) was injected i.p. into the animals $30 \mathrm{~min}$ before the p.o. administration of compound FCS303 (100 and $200 \mathrm{mg} / \mathrm{kg})$, selegiline $(10 \mathrm{mg} / \mathrm{kg}$ ), or vehicle. L-DOPA plus carbidopa (100 and $10 \mathrm{mg} / \mathrm{kg}$, respectively) were administrated i.p. 30 min later to all treatment groups. Locomotor activity was evaluated in the open-field test for a duration of $5 \mathrm{~min}$, at 2 and $24 \mathrm{~h}$ after administration of reserpine.

\section{Anti-cataleptic activity}

Catalepsy caused by haloperidol (Kikuchi et al., 1997; Schmidt et al., 2002; Wei, Chen, 2009) manifests as a prolonged stay of both forepaws in an atypical position on a horizontal bar. Haloperidol $(3 \mathrm{mg} / \mathrm{kg}$ ) was injected i.p. into the animals $30 \mathrm{~min}$ after the administration of compound FCS303 (100 mg/kg, p.o.), L-DOPA/carbidopa (400 mg/kg/40 mg/kg; p.o.), or vehicle (p.o.). The reversal of catalepsy was evaluated for a period of $2 \mathrm{~min}$ at $60 \mathrm{~min}$ after administration of treatments.

\section{Antioxidant activity ex vivo}

Mice were dosed daily for 10 days with FCS303 (50 mg/kg, p.o.), L-DOPA/carbidopa (400 mg/kg/ $40 \mathrm{mg} / \mathrm{kg}$, p.o.), or vehicle (p.o.), $30 \mathrm{~min}$ before haloperidol (1 mg/kg, i.p.) administration. Animals were killed by decapitation, and the brains were rapidly removed, washed $(\mathrm{KCl} 1 \%)$, and dissected on an ice-cold plate. Homogenates were obtained by homogenization of tissue in $50 \mathrm{mM}$ Tris-HCl buffer ( $\mathrm{pH}$ 7.4). Homogenates were centrifuged $\left(10000 \mathrm{rpm}\right.$ for $10 \mathrm{~min}$ at $\left.4{ }^{\circ} \mathrm{C}\right)$. The final supernatant were stored at $-20^{\circ} \mathrm{C}$. The protein content of each sample was determined by the Bradford method.

\section{Index of lipid peroxidation in brain homogenates}

This assay followed the protocol described by Hijova, Nistiar and Sipulova (2005). As such, $50 \mu \mathrm{L}$ of 50 $\mathrm{mM}$ phosphate buffer ( $\mathrm{pH} 7.4$ ) and $1 \mathrm{~mL}$ trichloroacetic acid $(10 \%)$ were added to brain homogenate $(450 \mu \mathrm{L})$, which was then centrifuged at $1850 \mathrm{xg}$ for $10 \mathrm{~min}$ at $4^{\circ} \mathrm{C}$. Next, $1 \mathrm{~mL}$ of thiobarbituric acid $(0.67 \%)$ was added to $1 \mathrm{~mL}$ of supernatant. This mixture was heated to $92^{\circ} \mathrm{C}$ for $30 \mathrm{~min}$, and then cooled in an ice bath $\left(4^{\circ} \mathrm{C}\right)$ before the absorbance was measured at $532 \mathrm{~nm}$. The results are expressed as thiobarbituric acid reactive substances, TBARS ( $\mathrm{mmol} / \mathrm{mL} / \mathrm{mg}$ ), of tissue protein.

\section{Quantification of protein carbonyl groups}

Quantification of protein carbonyl groups was performed using the technique of Levine et al. (1990), and following the protocol described by Baltacioglu et al. (2008). Briefly, $250 \mu \mathrm{L}$ of $2 \mathrm{M} \mathrm{HCl}$ or $250 \mu \mathrm{L}$ of $10 \mathrm{mM}$ 2,4-dinitrophenylhydrazine (DNPH) was added to brain homogenate $(50 \mu \mathrm{L})$ for the blank or sample, respectively. The samples were left in the dark at room temperature for $1 \mathrm{~h}$ and vigorously stirred every $15 \mathrm{~min}$. Next, $500 \mu \mathrm{L}$ of trichloroacetic acid (20\%) was added. The samples were kept in an ice bath for $15 \mathrm{~min}$ and then centrifuged at $11000 \mathrm{rpm}$ for $5 \mathrm{~min}$. The supernatant was removed and the pellet was washed three times with $1 \mathrm{~mL}$ of ethanol/ ethyl acetate (1:1) solution. After each wash, the sample was centrifuged for $7 \mathrm{~min}$ at $3000 \mathrm{rpm}$. The pellet was dissolved in $250 \mu \mathrm{L}$ of $6 \mathrm{M}$ guanidine hydrochloride and incubated at $37^{\circ} \mathrm{C}$ for $10 \mathrm{~min}$. The absorbance was determined at $360 \mathrm{~nm}$. The content of carbonyl groups was calculated based on the molar extinction coefficient of DNPH $\left(\varepsilon=22000 \mathrm{~cm}^{-1} \mathrm{M}^{-1}\right)$, and is expressed as nmol/ mg protein (Baltacioglu et al., 2008).

\section{Statistical analysis}

Results are expressed as mean \pm standard error of the mean (SEM). One-way analysis of variance (ANOVA) was performed, followed by the Tukey test to determine the treatments responsible for the significant differences. When variance was not homogeneous, or the data was not normally distributed, the Kruskal-Wallis test was applied, 
followed by the Dunn test. Analyses were performed using GraphPad Prism (v. 5.03).

\section{Ethical considerations}

The experimental protocols were evaluated and approved in a meeting held on October 18, 2011 (Act No. 06), by the Faculty of Science Ethics Committee, Universidad Nacional de Colombia.

\section{RESULTS AND DISCUSSION}

In this study the new coumarin FCS303, 8-propyl$6 \mathrm{H}-[1,3]$ dioxolo[4,5-g] chromen-6-one (Figure 1), was synthesized.

\section{In vitro inhibition of $\mathrm{MAO}$}

The ability of the coumarin analogue to inhibit the A and $\mathrm{B}$ isoforms of MAO was evaluated. The corresponding $\mathrm{IC}_{50}$ values and the selectivity indices $\left[\mathrm{IC}_{50}(h \mathrm{MAO}-\mathrm{A})\right] /$ $\left[\mathrm{IC}_{50}(h \mathrm{MAO}-\mathrm{B})\right]$ are shown in Table I.

The FCS303 compound showed selective inhibitory activity towards MAO-B, while MAO-A was not inhibited, even at the highest tested concentration. The new compound and reference inhibitors did not react directly with the Amplex ${ }^{\circledR}$ Red reagent, which indicates that these drugs do not interfere with the measurements.

The structure of FCS303, 8-propyl-6H-[1,3] dioxolo[4,5-g]chromen-6-one, has substitutions in the positions 4,6 , and 7 . Previous studies have shown that the substitution of hydrogens at positions 4 and 7 seems to increase the inhibitory potency of MAO (Santana et al., 2006). Substitutions at position 3 and/or 4 of the coumarin nucleus also contribute to the modulation of the inhibitory activity of MAO-B and the A/B selectivity (Gnerre et al., 2000). In position 7, the steric and lipophilic nature, and the electron characteristics, may be decisive in the formation of covalent bonds with the flavin ring of the flavín adenín dinucleótido (FAD) cofactor (Catto et al., 2006), which is present in the active site of the enzyme MAO. Inhibitors of MAO-B, such as rasagiline and selegiline, bind covalently to FAD, specifically the N-5 flavin (Jenner, 2012; Finberg, 2014).

Altough FCS303 is much less potent than selegiline in in vitro $\mathrm{hMAO}$ inhibition assay (Table I); their $\mathrm{IC}_{50}$ is comparable to iproniazide, a drug previously used clinically as an antidepressant. Moreover, several compounds (including some coumarins) were reported as inhibitors of MAO-B with $\mathrm{IC}_{50}$ values in the micromolar range (Tripathi et al., 2018). Finally, FCS303 has selectivity for hMAO-B, therefore, is reasonable to consider that it could be eventually useful for adjuvant for PD treatment.

\section{In vivo assays}

\section{Non-reserpinized mice}

Doses of 50 and $200 \mathrm{mg} / \mathrm{kg}$ of compound FCS303 caused a significant decrease in the locomotor activity at $23.5 \mathrm{~h}$, in mice that did not previously receive reserpine (Figure 2B), compared to the control group. No difference was detected at $1.5 \mathrm{~h}$ (Figure 2A). Although there are differences in locomotor activity induced by FCS303 between $1.5 \mathrm{~h}$ and $23.5 \mathrm{~h}$ this could be explained by the open field habituation (Haleem, Inam, Haleem, 2015).

In other studies, MAO-B inhibitors, including selegiline, have been found to reduce motor activity (Abel, 1995; Matos et al., 2013). On the other hand, a mechanism of action more complex than the inhibition of MAO-B could be present. However, the decrease in motor activity was an opposite effect to that obtained in the reserpine model and in L-DOPA/carbidopa potentiation, in which reversal of hypokinesia was observed. This supports the possible anti-parkinsonian activity of this coumarin.

TABLE I - In vitro $h \mathrm{MAO}-\mathrm{A}$ and $h \mathrm{MAO}-\mathrm{B}$ inhibitory activities of compound FCS303 and reference compounds ${ }^{\mathrm{a}}$

\begin{tabular}{lccc}
\hline Compounds & $\boldsymbol{h M A O - \mathbf { A } ^ { 1 }}\left(\mathbf{I C}_{\mathbf{5 0}}\right)$ & $\left.\boldsymbol{h M A O}^{\mathbf{2}} \mathbf{( I C}_{\mathbf{5 0}}\right)$ & Selectivity index $^{\mathbf{b}}$ \\
\hline FCS303 & $*$ & $5.46 \pm 0.36 \mu \mathrm{M}$ & $>18^{\mathrm{c}}$ \\
Clorgiline & $4.46 \pm 0.32 \mathrm{nM}$ & $61.35 \pm 1.13 \mu \mathrm{M}$ & 0.000073 \\
Selegiline & $67.25 \pm 1.02 \mu \mathrm{M}$ & $19.60 \pm 0.86 \mathrm{nM}$ & 3.43 \\
Iproniazide & $6.56 \pm 0.76 \mu \mathrm{M}$ & $7.54 \pm 0.36 \mu \mathrm{M}$ & 0.87 \\
\hline
\end{tabular}

${ }^{\mathrm{a}}$ Each $\mathrm{IC}_{50}$ value is the mean \pm standard error of the mean (S.E.M.) from five experiments $(\mathrm{n}=5) .{ }^{\mathrm{b}} h \mathrm{MAO}-\mathrm{B}$ selectivity ratios $\left[\mathrm{IC}_{50}(h \mathrm{MAO}-\mathrm{A})\right] /\left[\mathrm{IC}_{50}(h \mathrm{MAO}-\mathrm{B})\right]$ for inhibitory effects of FCS303 compound and reference inhibitors. ${ }^{\mathrm{c}}$ Value obtained under the assumption that the corresponding $\mathrm{IC}_{50}$ against $h \mathrm{MAO}-\mathrm{A}$ is the highest concentration tested $(100 \mu \mathrm{M}) .{ }^{*}$ Inactive at $100 \mu \mathrm{M}$ (highest concentration tested). ${ }^{1}$ Human monoamine oxidase A ( $\left.h \mathrm{MAO}-\mathrm{A}\right) .{ }^{2}$ Human monoamine oxidase B $(h \mathrm{MAO}-\mathrm{B})$ 


\section{A}

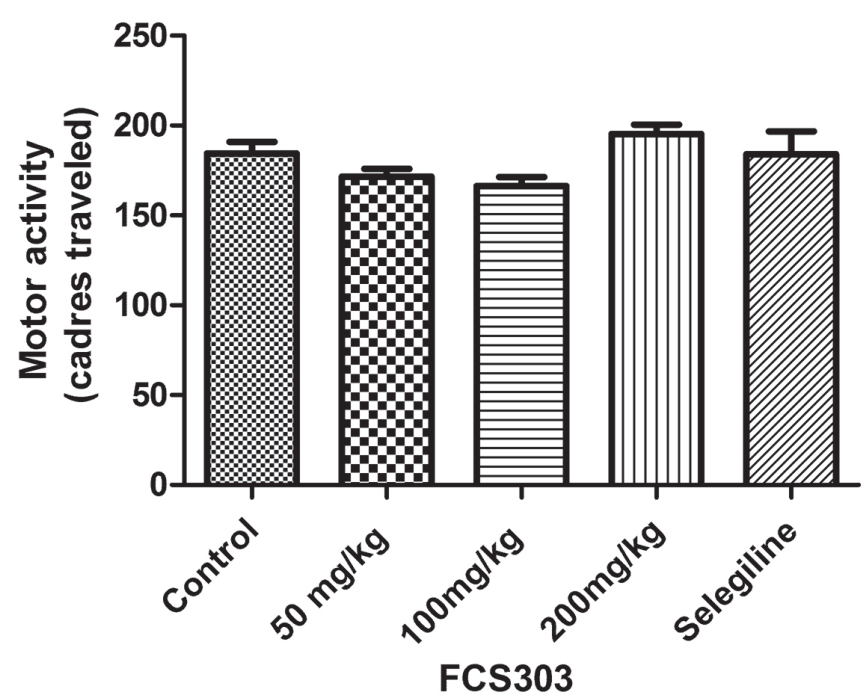

FIGURE 2A - Effect of administration of FCS303 (50, 100, and $200 \mathrm{mg} / \mathrm{kg}$ ), control (vehicle $0.1 \mathrm{~mL} / 10 \mathrm{~g}$ body weight), or selegiline $(10 \mathrm{mg} / \mathrm{kg})$ on motor activity in non-reserpinized mice. The animals were observed in an open-field test at $1.5 \mathrm{~h}$ after administration of compound FCS303. $\mathrm{n}=7-9 .{ }^{*} \mathrm{p}<0.05$ compared to the control group.

\section{Reserpine model}

Anti-parkinsonian effects were evaluated with the reserpine model. After $24 \mathrm{~h}$, the compound FCS303

A

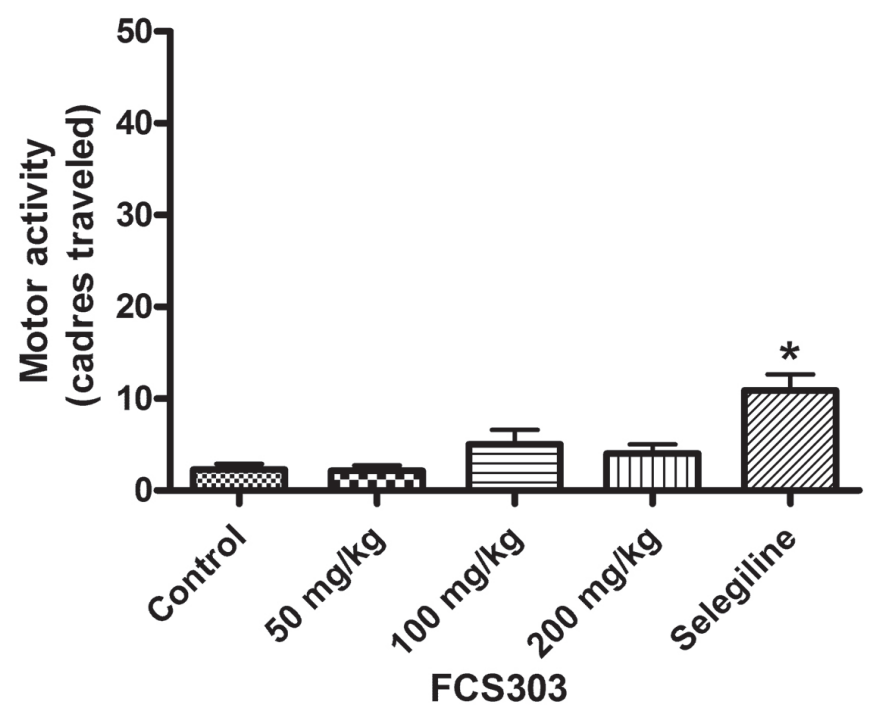

FIGURE 3A - Effect of administration of FCS303 (50, 100, and $200 \mathrm{mg} / \mathrm{kg}$ ), control (vehicle $0.1 \mathrm{~mL} / 10 \mathrm{~g}$ body weight), or selegiline $(10 \mathrm{mg} / \mathrm{kg})$ on motor activity in mice treated with reserpine $(3 \mathrm{mg} / \mathrm{kg})$. The animals were observed in the openfield test $2 \mathrm{~h}$ after administration of reserpine. $\mathrm{n}=7-9 .{ }^{*} \mathrm{p}<0.05$ compared to the control group.
B

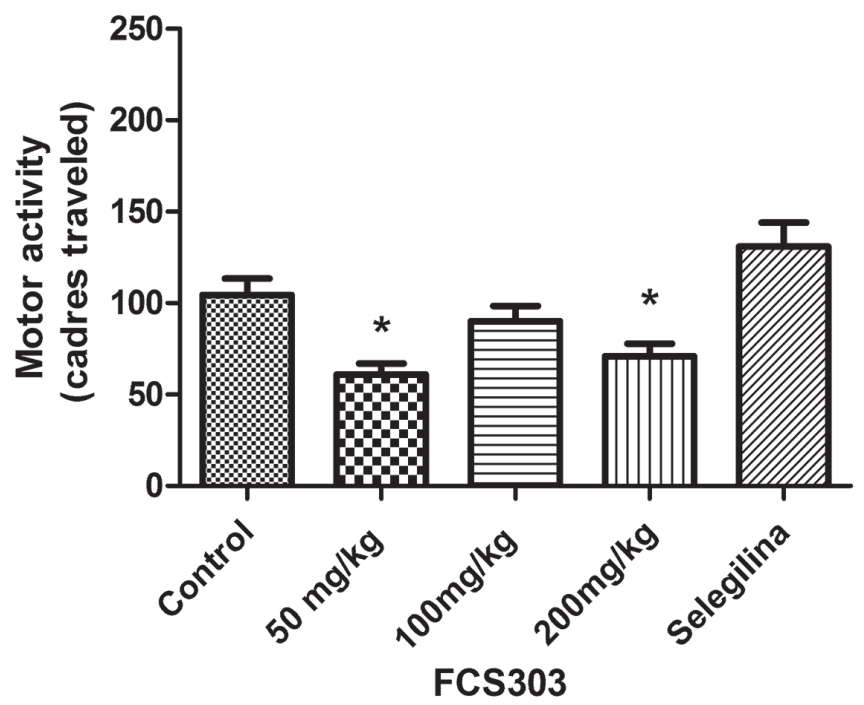

FIGURE 2B - Effect of administration of FCS303 (50, 100, and $200 \mathrm{mg} / \mathrm{kg}$ ), control (vehicle $0.1 \mathrm{~mL} / 10 \mathrm{~g}$ body weight), or selegiline $(10 \mathrm{mg} / \mathrm{kg})$ on motor activity in non-reserpinized mice. The animals were observed in an open-field test at $23.5 \mathrm{~h}$ after administration of compound FCS303. $\mathrm{n}=7-9 .{ }^{*} \mathrm{p}<0.05$ compared to the control group.

showed a statistically significant difference compared to the control at doses of 100 and $200 \mathrm{mg} / \mathrm{kg}$ (Figure 3B), whereas no difference was detected at $2 \mathrm{~h}$ (Figure $3 \mathrm{~A}$ ).

B

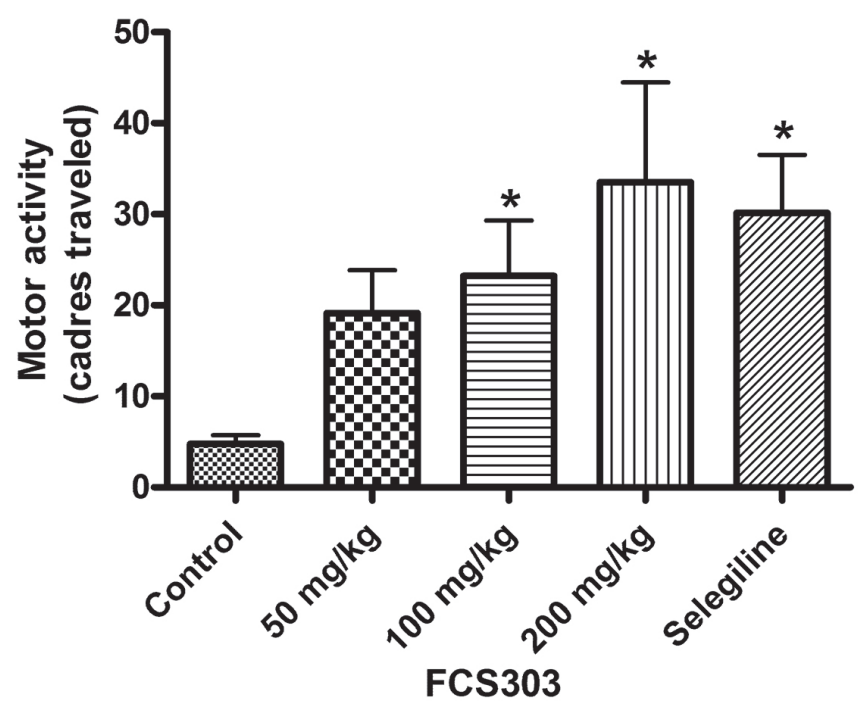

FIGURE 3B - Effect of administration of FCS303 (50, 100, and $200 \mathrm{mg} / \mathrm{kg}$ ), control (vehicle $0.1 \mathrm{~mL} / 10 \mathrm{~g}$ body weight), or selegiline $(10 \mathrm{mg} / \mathrm{kg})$ on motor activity in mice treated with reserpine $(3 \mathrm{mg} / \mathrm{kg})$. The animals were observed in the openfield test $24 \mathrm{~h}$ after administration of reserpine. $\mathrm{n}=7-9$. ${ }^{*} \mathrm{p}<$ 0.05 compared to the control group. 
The effect of reserpine on spontaneous locomotor activity is frequently used as a model of the motor disturbances associated with PD (Colpaert, 1987; Kaur, Starr, 1995; Menzaghi et al., 1997; Tadaiesky et al., 2006). Several drugs currently on the market were tested using this model, supporting its predictive validity (Menzaghi et al., 1997; Tadaiesky et al., 2006).

Selegiline and the compound FCS303 caused the reversal of hypokinesia in the reserpine model of Parkinson's. This effect was evident because reserpine blocks the vesicular monoamine transporter and produces a profound and lasting decrease in catecholamine. This situation causes depletion of DA in all dopaminergic nerve terminals, including the nigrostriatal pathway, leading to hypokinesia in animals (Philippens, 2008; Matos et al., 2013). MAO inhibitors reduce the enzymatic degradation of DA by monoamine oxidase, thus leading to an increase in the monoamine (Foley, 2000). DA acts on the postsynaptic receptors $\mathrm{D}_{1}$ and $\mathrm{D}_{2}$, which control movement (Fisher et al., 2000).

\section{Potentiation of effect of L-DOPA/carbidopa in mice pre-treated with reserpine}

The doses of FCS303 compound that showed

A

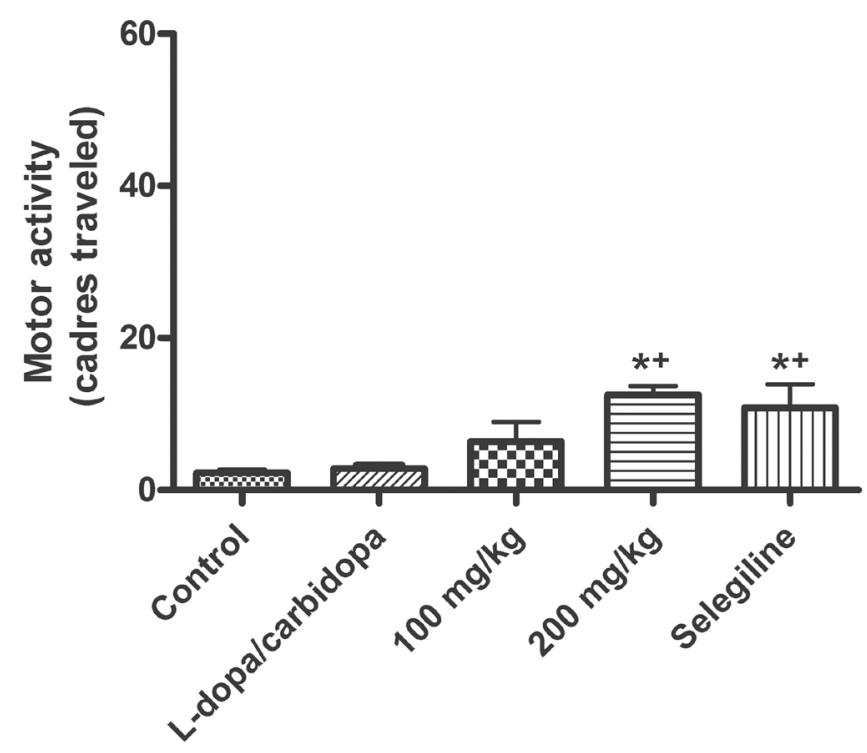

FCS 303

FIGURE 4A - Effect of administration of levodopa/carbidopa (100/10 mg/kg) plus FCS303 (100 and $200 \mathrm{mg} / \mathrm{kg}$ ), control (vehicle $0.1 \mathrm{~mL} / 10 \mathrm{~g}$ body weight), or selegiline $(10 \mathrm{mg} / \mathrm{kg})$ on motor activity in mice pre-treated with reserpine $(3 \mathrm{mg} / \mathrm{kg})$. The animals were observed in an open-field test $2 \mathrm{~h}$ after administration of reserpine. $n=7-9 . * p<0.05$ compared to the control group. ${ }^{+} \mathrm{p}<0.05$ compared to the group of levodopa/ carbidopa $(100 / 10 \mathrm{mg} / \mathrm{kg})$ alone in reserpinized animals. the best response in the Parkinson's reserpine model were evaluated. Selegiline and the FCS303 compound increased the response of L-DOPA/carbidopa and caused a significant reversal of the effects of reserpine, compared to the control and the group of levodopa/carbidopa $(100 / 10 \mathrm{mg} / \mathrm{kg}$ ) alone in reserpinized animals (Figures 4A and $4 \mathrm{~B})$.

The compound FCS303 showed a slightly higher response in the levodopa/carbidopa potentiation than in the reserpine model. FCS303 showed a statistically significant response at $200 \mathrm{mg} / \mathrm{kg}$, and a marked tendency towards increased locomotion at $100 \mathrm{mg} / \mathrm{kg}$, compared to the control group. This suggests that the compound can have a potentiating effect with low doses of L-DOPA/ carbidopa, probably because the MAO-B inhibitor can prevent degradation of DA derived from L-DOPA after the action of the aromatic L-amino acid decarboxylase in the brain. This is an important property because currently, one clinical use of selective MAO-B inhibitors such as selegiline and rasagiline, is to improve the response to L-DOPA at later stages of the disease (Finberg, 2014).

Anti-cataleptic activity

The coumarin analogue FCS303 and L-DOPA/

B

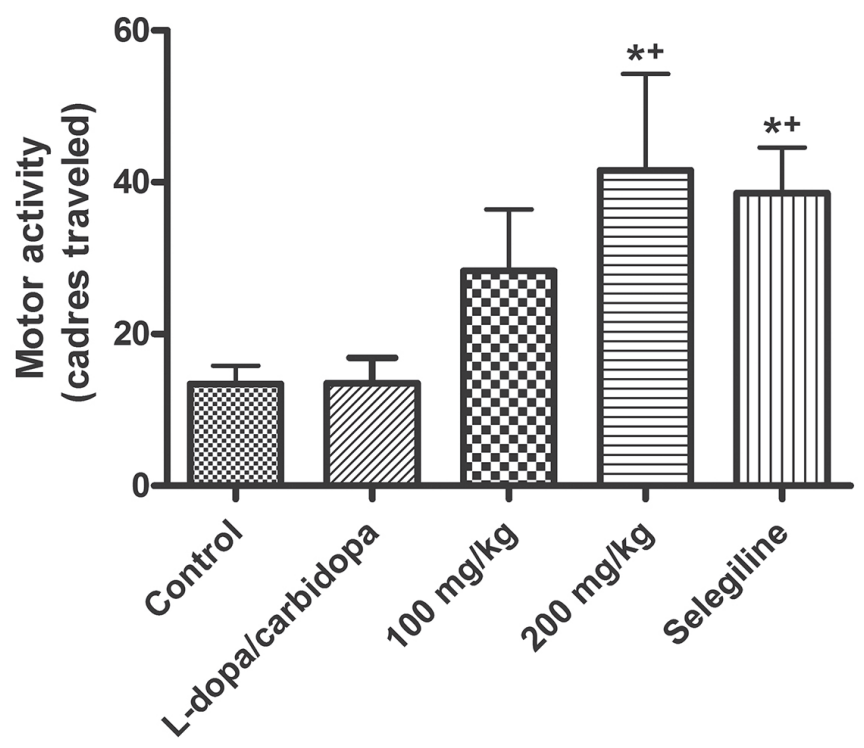

FCS 303

FIGURE 4B - Effect of administration of levodopa/carbidopa (100/10 mg/kg) plus FCS303 (100 and $200 \mathrm{mg} / \mathrm{kg}$ ), control (vehicle $0.1 \mathrm{~mL} / 10 \mathrm{~g}$ body weight), or selegiline $(10 \mathrm{mg} / \mathrm{kg})$ on motor activity in mice pre-treated with reserpine $(3 \mathrm{mg} / \mathrm{kg})$. The animals were observed in an open-field test $24 \mathrm{~h}$ after administration of reserpine. $\mathrm{n}=7-9 .{ }^{*} \mathrm{p}<0.05$ compared to the control group. ${ }^{+} \mathrm{p}<0.05$ compared to the group of levodopa/ carbidopa $(100 / 10 \mathrm{mg} / \mathrm{kg})$ alone in reserpinized animals. 
carbidopa produced a significant decrease in dwell time on the horizontal bar at $60 \mathrm{~min}$ (Figure 5). No cataleptic effects were observed after administration of these treatments (data not shown), in mice that did not receive haloperidol.

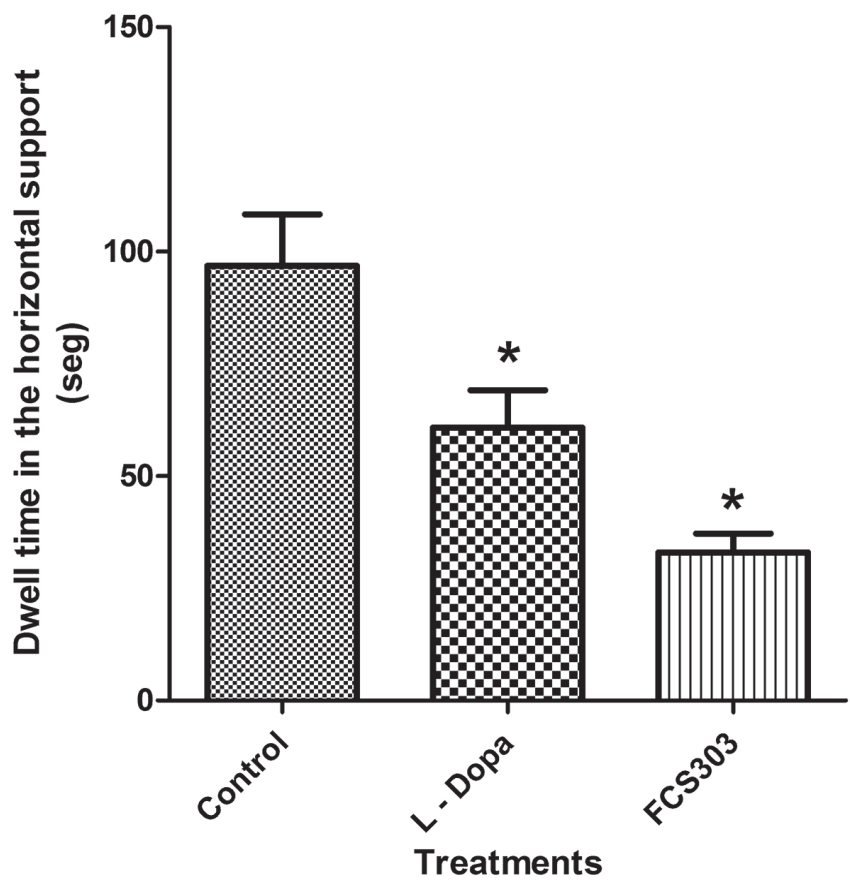

FIGURE 5 - Effect of administration of FCS303 $(100 \mathrm{mg} / \mathrm{kg})$, control (vehicle $0.1 \mathrm{~mL} / 10 \mathrm{~g}$ body weight), or levodopa/ carbidopa $(400 / 40 \mathrm{mg} / \mathrm{kg}$ ) on catalepsy induced by haloperidol $(3 \mathrm{mg} / \mathrm{kg})$. Catalepsy in mice was assessed using the horizontal bar test 60 min after administration of treatments. $\mathrm{n}=8$. $* p<0.05$ compared to the control group.

The reference compounds and the coumarin analogue FCS303 showed anti-cataleptic effects in the haloperidol model, a dopamine $\mathrm{D}_{2}$ receptor antagonist drug. This model can predict the activity of dopaminergic and non-dopaminergic drugs in PD. It induces a catalepticlike state that can be reversed by such drugs. This condition is in some ways analogous to the inability of PD patients to initiate movements (Duty, Jenner, 2011).

\section{Antioxidant activity ex vivo}

\section{Index of lipid peroxidation in brain homogenates}

The brains of mice treated with FCS303 and L-DOPA/carbidopa presented lower TBARS levels compared to control animals (Figure 6).

\section{Quantification of protein carbonyl groups}

Protein oxidation products were lower in brains treated with the compound FCS303 and L-DOPA/ carbidopa, compared to the control animals (Figure 7).

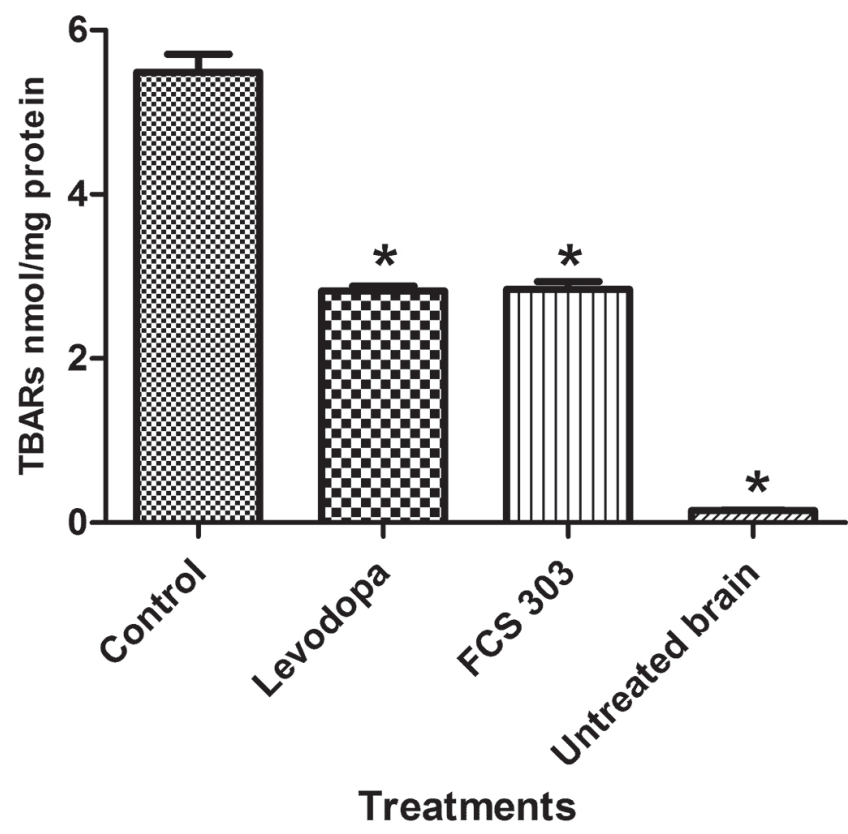

FIGURE 6 - Effect of administration of FCS303 $(50 \mathrm{mg} / \mathrm{kg})$, control (vehicle $0.1 \mathrm{~mL} / 10 \mathrm{~g}$ body weight), or levodopa/ carbidopa $(400 / 40 \mathrm{mg} / \mathrm{kg})$ on lipid peroxidation in brain homogenates of mice treated with haloperidol $(1 \mathrm{mg} / \mathrm{kg})$ for 10 days. $\mathrm{n}=8$ mice. ${ }^{*} \mathrm{p}<0.05$ compared to the control group.

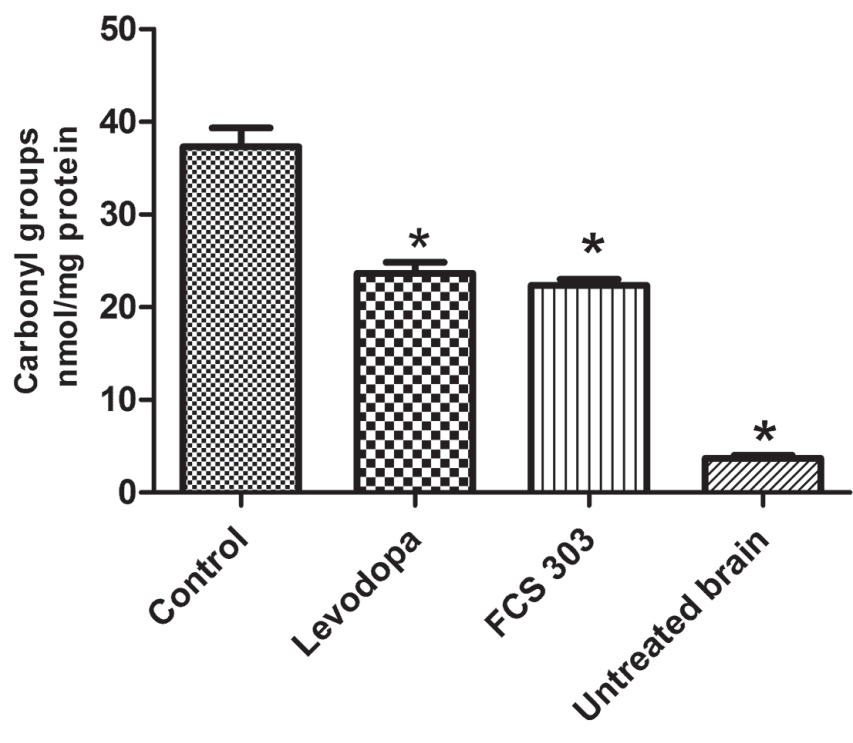

Treatments

FIGURE 7 - Effect of administration of FCS303 $(50 \mathrm{mg} / \mathrm{kg})$, control (vehicle $0.1 \mathrm{~mL} / 10 \mathrm{~g}$ body weight), or levodopa/ carbidopa $(400 / 40 \mathrm{mg} / \mathrm{kg})$ on the oxidation of carbonyl groups of proteins in brain homogenates of mice treated with haloperidol $(1 \mathrm{mg} / \mathrm{kg})$ for 10 days. $\mathrm{n}=8$ mice. ${ }^{*} \mathrm{p}<0.05$ compared to the control group.

The levels of TBARS and carbonyl groups in brain homogenates of animals that had not undergone any type of procedure with haloperidol (untreated) were lower than 
the levels of the control and treatment groups (Figures 6 and 7). These results are consistent with several studies in which chronic administration of haloperidol was associated with increased levels of lipid peroxidation and decreased levels of reduced glutathione and antioxidant enzymes (catalase and superoxide dismutase), leading to oxidative stress (Bishnoi, Chopra, Kulkarni, 2006; Bishnoi, Chopra, Kulkarni, 2007). Nevertheless, FCS303 offered a significant protective effect compared to the control animals, probably because the blockade of $\mathrm{D}_{2}$ receptors by haloperidol resulted in increased dopamine turnover. This, in turn, could have conceivably lead to an increased production of hydrogen peroxide and other toxic dopamine metabolites, resulting in increased oxidative stress (Naidu, Singh, Kulkarni, 2003; Singh et al., 2003). Inhibitors of MAO-B would be predicted to reduce oxidative stress by reducing $\mathrm{H}_{2} \mathrm{O}_{2}$ production, thus functioning as neuroprotective agents (Foley et al., 2000).

\section{CONCLUSION}

According to the current study, it could be concluded that the synthetic coumarin FCS303 (8-propyl-6H- [1,3] dioxolo [4,5-g] chromen-6-one) has interesting properties, such as selective inhibitory activity on $h \mathrm{MAO}-\mathrm{B}$ and anti-parkinsonian activity in in vivo models of PD. It is important to continue studying this coumarin analogue because it could be a possible anti-parkinsonian agent.

\section{ACKNOWLEDGMENTS}

This work was conducted with funding from Universidad Nacional de Colombia, Bogotá (VRI/DIB, Project: 13668). The authors would like to thank the Grupo de Principios Bioactivos en Plantas Medicinales (COL0014832).

\section{REFERENCES}

Abel E. Behavioral effects of isatin on open field activity and immobility in the forced swim test in rats. Physiol Behav. 1995;57(3):611-3.

Alexi T, Borlongan C, Faull R, Williams C, Clark R, Gluckman $\mathrm{P}$, et al. Neuroprotective strategies for basal ganglia degeneration: Parkinson's and Huntington's diseases. Prog Neurobiol. 2000;60(5):409-70.
Ariza S, Rueda D, Rincón J, Linares E, Guerrero M. Efectos farmacológicos sobre el sistema nervioso central inducidos por cumarina aislada de Hygrophila tyttha Leonard. Vitae. 2007;14(2):51-8.

Baltacioglu E, Akalin FA, Alver A, Deger O, Karabulut E. Protein carbonyl levels in serum and gingival crevicular fluid in patients with chronic periodontitis. Arch Oral Biol. 2008;53(8):716-22.

Bishnoi M, Chopra K, Kulkarni S. Involvement of adenosinergic receptor system in an animal model of tardive dyskinesia and associated behavioural, biochemical and neurochemical changes. Eur J Pharmacol. 2006;552(1-3):55-66.

Bishnoi M, Chopra K, Kulkarni S. Possible anti-oxidant and neuroprotective mechanisms of zolpidem in attenuating typical anti-psychotic-induced orofacial dyskinesia: A biochemical and neurochemical study. Prog Neuropsychopharmacol Biol Psychiatry. 2007;31(5):1130-8.

Catto M, Nicolotti O, Leonetti F, Carotti A, Favia A, Soto-Otero $\mathrm{R}$, et al. Structural insights into monoamine oxidase inhibitory potency and selectivity of 7-substituted coumarins from ligandand target- based approaches. J Med Chem. 2006;49(16):491225.

Colpaert F. Pharmacological characteristics of tremor, rigidity and hypokinesia induced by reserpine in rats. Neuropharmacology. 1987;26(9):1431-40.

Duty S, Jenner P. Animal models of Parkinson's disease: A source of novel treatments and clues to the cause of the disease. Br J Pharmacol. 2011;164(4):1357-91.

Emborg M. Evaluation of animal models of Parkinson's disease for neuroprotective strategies. J Neurosci Methods. 2004;139(2):121-43.

Epifano F, Molinaro G, Genovese S, Ngomba R, Nicoletti F, Curini M. Neuroprotective effect of prenyloxycoumarins from edible vegetables. Neurosci Lett. 2008;443(2):57-60.

Finberg J. Update on the pharmacology of selective inhibitors of MAO-A and MAO-B: Focus on modulation of CNS monoamine neurotransmitter release. Pharmacol Ther. 2014;143(2):133-52. 
Fisher A, Biggs C, Eradiri O, Starr M. Dual effects of L-3,4-dihydroxyphenylalanine on aromatic L-amino acid decarboxylase, dopamine release and motor stimulation in the reserpine-treated rat: Evidence that behavior is dopamine independent. Neuroscience. 2000;95(1):97-111.

Foley P, Gerlach M, Youdim M, Riederer P. MAO-B inhibitors: Multiple roles in the therapy of neurodegenerative disorders? Parkinsonism Relat Disord. 2000;6(1):25-32.

Gershanik OS. Improving L-DOPA therapy: The development of enzyme inhibitors Mov Disord. 2015;30(1):103-13.

Gnerre C, Catto M, Francesco L, Weber P, Carrupt P, Altomare $\mathrm{C}$, et al. Inhibition of monoamine oxidase by functionalized coumarin derivatives: Biological activities, QSAR, and 3D-QSARs. J Med Chem. 2000;43(25):4747-58.

Haleem D, Inam Q, Haleem M. Effects of clinically relevant doses of methyphenidate on spatial memory, behavioral sensitization and open field habituation: A time related study. Behav Brain Res. 2015;281:208-14.

Hijova E, Nistiar F, Sipulova A. Changes in ascorbic acid and malondialdehyde in rats after exposure to mercury. Bratis Lek Listy. 2005;106(8-9):248-51.

Jenner P. Mitochondria, monoamine oxidase B and Parkinson's disease. Basal Ganglia. 2012;2(4 Suppl):S3-S7.

Kang S, Lee K, Sung S, Kim Y. Four new neuroprotective dihydropyranocoumarins from Angelica gigas. J Nat Prod. 2005;68(1):56-9.

Kaur S, Starr M. Antiparkinsonian action of dextramethorphan in the reserpine-treated mouse. Eur J Pharmacol. 1995;280(2):15966.

Kikuchi T, Uwahodo Y, Tottori K, Nakai M, Morita S. The attenuating effect of carteolol hydrochloride, a $\beta$-adrenoceptor antagonist, on neuroleptic induced catalepsy in rats. Psychopharmacol. 1997;131(2):108-14.

Levine R, Garland D, Oliver C, Amici A, Climent I, Lenz A, et al. Determination of carbonyl content in oxidatively modified proteins. Methods Enzymol. 1990;186:464-78.

Matos M, Viña D, Janeiro P, Borges F, Santana L, Uriarte E. New halogenated 3-phenylcoumarins as potent and selective MAO-B inhibitors. Bioorg Med Chem Lett. 2010;20(17):5157-60.
Matos M, Viña D, Picciau C, Orallo F, Santana L, Uriarte E. Synthesis and evaluation of 6-methyl-3-phenylcoumarins as potent and selective MAO-B inhibitors. Bioorg Med Chem Lett. 2004;19(17):5053-5.

Matos M, Viña D, Quezada E, Picciau C, Delogu G. Orallo $\mathrm{F}$, et al. A new series of 3-phenylcoumarins as potent and selective MAO-B inhibitors. Bioorg Med Chem Lett. 2009;19(12):3268-70.

Matos M, Vilar S, Gonzalez-Franco R, Uriarte E, Santana L, Friedman C, et al. Novel (coumarin-3-yl) carbamates as selective MAO-B inhibitors: Synthesis, in vitro and in vivo assays, theoretical evaluation of ADME properties and docking study. Eur J Med Chem. 2013;63:151-61.

Menzaghi F, Whelan K, Risbrough V, Rao T, Lloyd G. Interactions between a novel cholinergic ion chanel agonist, SIB-1765F, and L-DOPA in the reserpine model of Parkinson's disease in rats. J Pharmacol Exp Ther. 1997;280(1):393-401.

Naidu P, Singh A, Kulkarni S. Quercetin, a bioflavonoid attenuated haloperidol induced orofacial dyskinesia. Neuropharmacology. 2003;44(8):1100-6.

Philippens I. Non-human primate models for Parkinson's disease. Drug Discov Today Dis Models. 2008;5(2):105-11.

Potdar M, Mohile S, Salunkhe M. Coumarin syntheses via Pechmann condensation in Lewis acidic chloroaluminate ionic liquid. Tetrahedron Lett. 2001;42(52):9285-7.

Santana L, Uriarte E, González-Díaz H, Zagotto G, Soto-Otero R, Méndez-Alvarez E. A QSAR model for in silico screening of MAO-A inhibitors. Prediction, synthesis, and biological assay of novel coumarins. J Med Chem. 2006;49(3):1149-56.

Schmidt W, Mayerhofer A, Meyer A, Kovar K. Ecstasy counteracts catalepsy in rats, an anti-parkinsonian effect? Neurosci Lett. 2002;330(3):251-4.

Singh A, Naidu P, Kulkarni S. Possible antioxidant and neuroprotective mechanisms of FK506 in attenuating haloperidol-induced orofacial dyskinesia. Eur J Pharmacol. 2003;477(2):87-94.

Tadaiesky M, Andreatini R, Vital M. Different effects of 7-nitroindazole in reserpine-induced hypolocomotion in two strains of mice. Eur J Pharmacol. 2006;535(1-3):199-207. 
Tripathi A, Upadhyay S, Paliwal S, Saraf S. Privileged scaffolds as MAO inhibitors: Retrospect and prospects. Eur J Med Chem. 2018;145:445-97.

Vergel N, López J, Orallo F, Viña D, Buitrago D, Olmo E, et al. Antidepressant-like profile and MAO-A inhibitory activity of 4-propyl-2H-benzo[h]- chromen-2-one. Life Sci. 2010;86(2122):819-24.
Wei L, Chen L. Effects of 5-HT in globus pallidus on haloperidolinduced catalepsy in rats. Neurosci Lett. 2009;454(1):49-52.

Yáñez M, Fraiz N, Cano E, Orallo F. Inhibitory effects of cisand trans-resveratrol on noradrenaline and 5-hydroxytryptamine uptake and on monoamine oxidase activity. Biochem Biophys Res Commun. 2006;344(2):688-95.

Received for publication on $02^{\text {nd }}$ October 2017 Accepted for publication on $17^{\text {th }}$ October 2018 